\title{
Neck Circumference as Useful Marker of Obesity and Its Correlation with Triglyceride Levels
}

\author{
Mutiara Indah Sari ${ }^{1}$, Zaimah Z Tala ${ }^{2}$, Dewi Indah Sari ${ }^{3}$ \\ ${ }^{1}$ Departement of Biochemistry, Faculty of Medicine, Sumatera Utara University, Indonesia \\ muti_dreyahoo.com \\ ${ }^{2}$ Departement of Clinical Nutrition, Faculty of Medicine, Sumatera Utara University, Indonesia \\ zaimahclinnuteyahoo. com \\ ${ }^{3}$ Departemen of Clinical Pathology, Faculty of Medicine, Sumatera Utara University, Indonesia \\ siregar.dewiindahsari@gmail.com
}

\begin{abstract}
Hypertriglyceridemia is a risk factor for metabolic syndrome and cardiovascular disease. Obesity often has a correlation with hypertriglyceridemia. Neck circumference (NC) is an anthropometric method of measuring upper body obesity. It is easy to use , innovative and time-saving. The aim of this study was to determine the relationship between $\mathrm{NC}$ and body mass index (BMI) as an useful marker of obesity and its correlation with triglyceride levels.

The study was an analyticalcross-sectional study. The subjects were 139 students of the Faculty of Medicine, University of Sumatera Utara, with inclusion and exclusion criteria. Height was measured with a microtoise, weight was measured with digital scales and $\mathrm{NC}$ was measured using a tape measure ONEMED. Triglyceride levels were measured using the cobas 600, series 501. Analysis of data was done using SPSS software. In the study of 139 subjects,the BMI, NC and triglyceride levels were $26.25 \mathrm{~kg} / \mathrm{m} 2,35.04 \mathrm{~cm}, 81.74 \mathrm{mg} / \mathrm{dl}$. Pearson's correlation coefficients indicated a significant association between $\mathrm{NC}$ and $\mathrm{BMI} r=0.576 ; p=0.000$, and $\mathrm{NC}$ with blood triglyceride $\mathrm{r}=$ $0.390 ; p=0.000$.

This study shows NC measurements can be used as identification of obesity and have correlation with triglyceride levels.
\end{abstract}

Keywords - Neck circumference, obesity, triglyceride level

\section{INTRODUCTION}

Triglycerides are the result of lipid metabolism, which serves as a source of energy for the body and also create cell membranes [1]. A high level of triglycerides in the blood, called hypertriglyceridemia, is a risk factor for cardiovascular disease and metabolic syndrome [2].

There is adirect correlation between the elevation of triglyceride levels and cardiovascular risk, evidenced by the elevation of triglycerides in the first 5 years that leadsto the incidence of cardiovascular disease in the next 5 years [3]. Hypertriglyceridemia prevalence will increase along with the increasing degree of obesity [4], [5].
Obesity is an accumulation of excessive fat tissue in the body. Hypertriglyceridemiain obese children will increase the incidence of metabolic syndrome in adulthood [6]. Screening for obesity is one way of early prevention of the risk of hypertriglyceridemia.

Anthropometric measurement is one of the simplest ways to screen obesity. Body Mass Index (BMI) is one of the most frequent anthropometric measurements used to assess obesity. However, this measurement is not accurate in particular situations.

The measurement of neck circumference (NC) as an index of upper body obesity is a simple screening measure to identify excess weight/ obesity. This technique is easy, innovative and time-saving. Research on NC states that the neck is a subcutaneous fat deposit, so NC measurement is considered as a good parameter in determining the risk of diseases associated with elevated levels of lipids, such as cardiovascular disease [7]. Another study found that there was relationship between $\mathrm{NC}$ and the incidence of metabolic syndrome [8].

Due to the simplicity and effectiveness of $\mathrm{NC}$ in detecting obesity related to subcutaneous fat deposit, it is necessary to study more about the application of these anthropometric measurements and their relationship with triglyceride levels.

\section{METHODS}

This study was conducted after obtaining approval from the Ethics Commission. The subjects were students of the Faculty of Medicine, University of Sumatera Utara in 2016, and aged 1623 years. They were asked to fill out and sign an 
informed consent after being given an explanation about the purpose and benefits of the research.

The study design was an analytical crosssectional study. The criteria for the inclusion of respondents in this study were that they were not currently taking lipid-lowering drugs (for 3 days prior to blood sampling); were not suffering from goiter disease, a thyroid tumor or enlarged lymph nodes; there were no abnormalities in the neck which could interfere with the measurement of neck circumference; and they were willing to be the subjects of the research. The criteria for the exclusion of respondents in this study were that they were not come to the NC measurement, blood sampling and were withdrawn from the research.

Anthropometric measurements like height was measured with a microtoise, weight was measured with digital scales. BMI was calculated using weight in $\mathrm{kg}$ divided by height in $\mathrm{m} 2$. NC was measured using standart measuring tape, ONEMED, close to $0,1 \mathrm{~cm}$. The NC measurement in female respondents was located between the mid cervical spine and the mid anterior neck, whereas the measurement in men was just below the laryngeal prominence (Adam's apple) or thyroid cartilage. The measurement of the respondents' anthropometric parameters, blood triglyceride levels in the research were conducted at the USU Hospital after fasting for at least 8-12 hours. The measurementof triglyceride levels was made using a cobas 600 series 501 .

Data were analyzed by univariate testing (subject characteristics, BMI, neck circumference and triglyceride levels) and the Pearson bivariate correlation test (NC relationship with weight, BMI and triglyceride levels) using SPSS 14.0 for windows. A curves catterplot test was done to identify the patterns of the relationships among the variables.

\section{RESULTS AND DISCUSSION}

Of the139 students who were willing to participate as student research respondents the gender distribution was 55 men and 84 women, with the characteristic mean of age was 19.20 \pm 1.08. The mean differences in weight, BMI, NC and triglyceride levels were: $20: 27 \pm 69.43,26.26 \pm$ 5.81, $35.04 \pm 4: 37,81.75 \pm 56.36$ Table 1 .
TABLE 1

CORRELATIONS BETWEEN NECK CIRCUMFERENCE AND OTHER MEASURES.

\begin{tabular}{|c|c|c|c|}
\hline$n=139$ & Mean \pm SD (Range) & $\begin{array}{c}\text { Correlation } \\
\text { (r) of NC } \\
\text { with }\end{array}$ & $\mathrm{p}$ \\
\hline Age (year) & $19.20 \pm 1.08(16,23)$ & 0.166 & 0.051 \\
\hline \multicolumn{4}{|l|}{ Anthropometry } \\
\hline $\begin{array}{c}\text { Body } \\
\text { Weight (kg) }\end{array}$ & $69.43 \pm 20.27(40,133)$ & $0.763 * *$ & 0.000 \\
\hline $\operatorname{BMI}\left(\mathrm{kg} / \mathrm{m}^{2}\right)$ & $26.26 \pm 5.81(16.41,44.37)$ & $0.579 * *$ & 0.000 \\
\hline $\begin{array}{l}\text { Triglyceride } \\
(\mathrm{mg} / \mathrm{d})\end{array}$ & $81.75 \pm 56.36(32.0,454.0)$ & $0.390 * *$ & 0.000 \\
\hline $\mathrm{NC}(\mathrm{cm})$ & $\begin{array}{l}35.04 \pm 4.37(21.50, \\
47.00)\end{array}$ & - & - \\
\hline
\end{tabular}

The Kolmogorov-Smirnov normality test results obtained a normal distribution of data. The Pearson correlation test showed no significant correlation ( $\mathrm{p}=0.051)$ between NC and age. Obesity as nutrition problems, increaseafter the age of 30 years. Respondents in this study were young adults with a similar age between 16-23 years (whose ages were not very different). This allowed the presence of a non-significant correlation between NC and age in this study.

This study showed a close and significant correlation between $\mathrm{NC}$ and body weight ( $\mathrm{p}=$ 0.000 ), with a pearson correlation value of 0.763 . These results are illustrated in Figure 1.

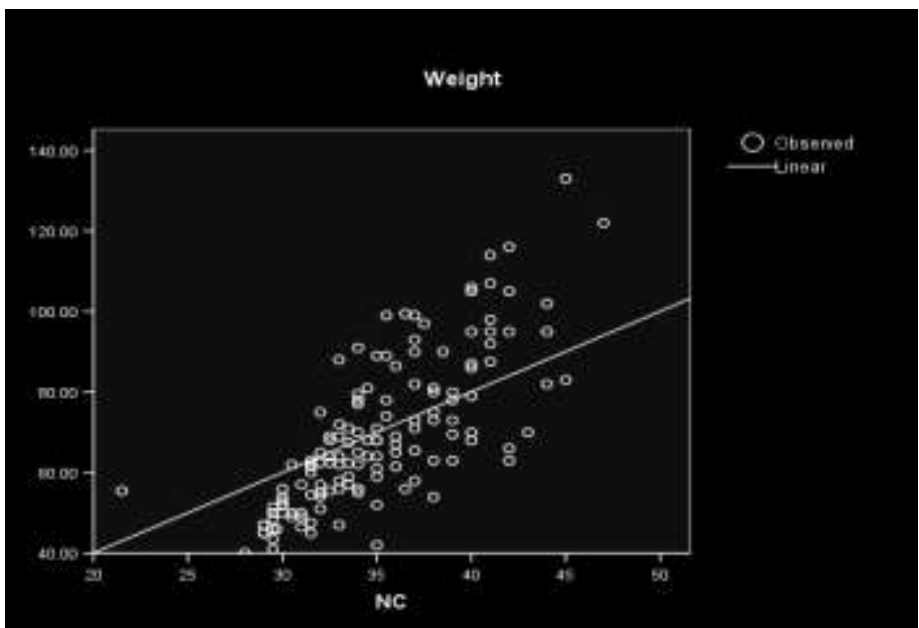

Fig 1. Scatter plot showing correlation $(\mathrm{r})$ of neck circumference $(\mathrm{NC} ; \mathrm{cm})$ with weight $(\mathrm{kg})$

The value of a positive correlation between these two variables showed a unidirectional relationship. If the weight increases, there is an increase in NC. The research is consistent with the research in 
Brazil, which shows the correlation between NCand weight gain in children [9]. Body weight is the result of an increase or decrease in the body's existing network. Excessive weight is a major factor in obesity. The weakness of weight measurement being an obesity index is that it does not describe the distribution of the body fat. Another anthropometric measurement is needed to determine the distribution of body fat, in addition to weight measurement, that can determine the risks of excess body fat against certain metabolic diseases.

A strong correlation was also seen in the relationship between $\mathrm{NC}$ and $\mathrm{BMI}(\mathrm{r}=0.579, \mathrm{p}=$ 0.000 ), and it has positive direction, which means that if the $\mathrm{NC}$ increases the value of the BMI also increases (Figure 2).

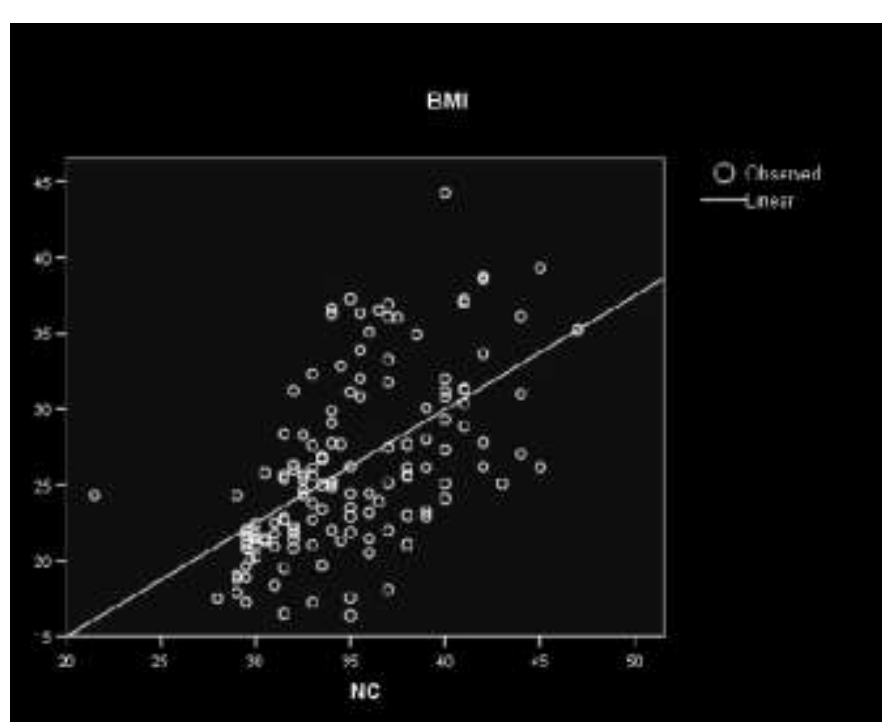

Fig 2. Scatter plot showing correlation (r) of neck circumference $(\mathrm{NC} ; \mathrm{cm})$ and body mass index (BMI; $\mathrm{kg} / \mathrm{m} 2)$

The present data are in accordance with Naliato et al [9] regarding BMI, which significantly correlated with waist and NC. Lou et al [10] also regarding the significance of correlations between neck circumference and BMI.

Anthropometric measurement is one of the simplest methods of screeningfor obesity. BMI is one of the most frequent anthropometric measurements used to assess obesity. The drawback of this measurement is that it is not accurate incertain conditions, such as an athleticbuild often being categorized as obese, while fat in the elderlyis not taken into consideration. Determination of percentile values and the use of tables in determining the classification of BMI in children are also reasons for measuringthe NCto identify obesity [11], [12].

Another drawback of BMI measurement is that it is unable to assess the distribution of fat accumulations in the body, and NC is one index of upper body fat distribution or upper body obesity. The advantages of the NC indexshoweda small error compared to the indices of other parameters and itcan also be used as an easy and inexpensive obesity screening [11], [12].

The correlation of NC and triglyceride levels in this study showsthat there is significant correlation $(p=0.000, r=0.390)$, the directionof which is also positive (Figure 3).

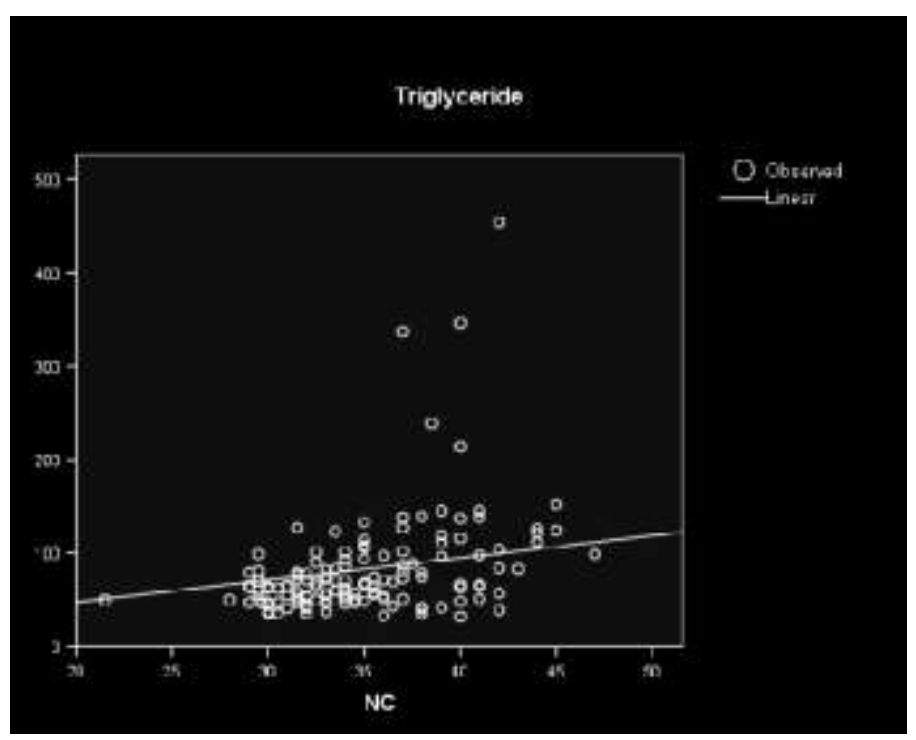

Fig 3. Scatter plot showing correlation $(\mathrm{r})$ of neck circumference $(\mathrm{NC} ; \mathrm{cm})$ and triglyceride $(\mathrm{mg} / \mathrm{dl})$

Vallianou et al [13] found similar results in adults, suggesting that NCisa powerful indicator of atherogenic dyslipidemia above and beyond the central obesity indicators.

Subcutaneous neck fat as part of the upper body can release free fatty acids in large amounts. Fat tissue lipolysis isinstrumental in increasing free fatty acids, so ifthe increase of free fatty acids is in excess, it can lead to increased levels of triglycerides in the blood [14]. The elevation of triglyceride levels is the primary risk factor for cardiovascular disease [15]. The activityof lipolysis at the NC has become one of the mechanisms that explains the relationship between NCand the risk of 
cardiovascular disease. It explains how the NC can also be used as a predictor of the risk of cardiovascular disease.

Another study explains that individuals with abnormal NCwill have a risk of elevated levels of triglycerides that can lead to metabolic syndrome and cardiovascular disease [16], [17].

\section{IV.CONCLUSION}

The results of this study indicate that $\mathrm{NC}$ as a parameter for upper-body anthropometry has a strong positive and significant correlation with weight and BMI. Thereis also a positive correlation between $\mathrm{NC}$ and triglyceride levels so that the measurement of NC can be used as an index of obesity and an indicator of cardiovascular disease.

\section{REFERENCES}

[1] Guyton AC, Hall JE. Lipid Metabolism. In: Textbook of Medical Physiology.Twelfth Edition. 2011. Philadelphia, Pa.: Saunders/Elsevier

[2] Rader DJ, Hobbs HH. Disorders of Lipoprotein Metabolism. Harrison's. Principles of Internal Medicine. 19th ed. New York: McGraw-Hill; 2015. Chapter 356.

[3]. Miller Michel, et al. Triglyserides and Cardiovascular Disease. A Scientific Statement From The America Hearth Association. Circulation. 2001; 123:2292-2333

[4]. Salvatore D, Satnick A, Abell R, et al. The prevalence of abnormal metabolic parameters in obese and overweight children. JPEN J Parenter Enteral Nutr. 2014;38:852-5.

[5]. Margolis KL, Greenspan LC, Trower NK, et al. Lipid screening in children and adolescents in community practice: 2007-2010. Circ Cardiovasc Qual Outcomes. 2014;7:718-26.

[6] Lloyd, L.J., S.C. Langley-Evans and S. McMullen, 2012. Childhood obesity and risk of the adult metabolic syndrome: a systematic review. Int. J. Obes., 36: 1- 11

[7] Onat A, Hergenc G, Yuksel H, Can G, Ayhan E, Kaya Z. Neck. circumference as a measure of central obesity: Associations with metabolic syndrome and obstructive sleep apnea syndrome beyond waist circumference. Clin Nutr 2009;28:46-51.

[8] Stabe C, Vasques A C J, Lima M M O, Tambascia M A, Pareja J C, Yamanaka A, Geloneze B Neck circumference as a simple tool for identifying the metabolic syndrome and insulin resistance: results from the Brazilian Metabolic Syndrome Study Clinical Endocrinology 2013; 786; 874-881,

[9] Naliato ECO, Oliveira VT, Oliveira LRM, Mello CF, Fernandes LB, Alves VD, Ferreira LAS, Moreira SV, Pandini RLM, Sena SSS, Souza LMBM. Evaluation of waist and neck circumferences in Brazilian school children. Edorium J Endocrinology. 2014;1;1-8
[10] Lou DH, Yin FZ, Ma CM, Liu XL, Lu Q. Neck circumference is an accurate and simple index for evaluating overweight and obesity in Han children. Ann Hum Biol 2012;39(2):161-165.

[11] LaBerge, Rbert C., J.P Vaccani \& R.M Gow . (2009). Inter and Intra Rater Reliability of Neck Circumference Measurements in Children.Pediatric Pulmonology Vol. 44: 64-69.

[12] Aswathappa, Jagadamba, Sumit Garg, Karthiyanee Kutty, VinuthaShankar. Neck circumference as an Anthropometric Measure of obesity in diabetics. North American Journal of Medical Sciences. 2013. Vol 5(1) :28-31.

[13] Vallianou NG, Evangelopoulos AA, Bountziouka V, Vogiatzakis ED, Bonou MS, Barbetseas J, et al. Neck circumference is correlated with triglycerides and inversely related with HDL cholesterol beyond BMI and waist circumference. Diabetes Metab Res Rev 2013;29(1):90-97.

[14] Preis SR, Pencina MJ, D’Aqoatino RB Sr, Meiqs JB, Vasan RS, Fox CS.Neck circumference and the development of cardiovascular disease risk factors in the Framingharm heart study. Diabetes Care 2013, 36:e3.

[15] John D, Brunzell MD. Hypertriglyceridemia. N Engl J Med 2007; 357: 1009-17.

[16] Jing-ya Zhou, et.al. Neck circumference as an independent predictive contributor to cardio-metabolic syndrome. Cardiovascular Diabetology 2013, 12:76.

[17] Gomez-Arbelaez D, Camacho P A, Cohen D D, Saavedra-Cortes S, Lopez-Lopez C, Lopez-Jaramillo P Neck circumference as a predictor of metabolic syndrome, insulin resistance and low-grade systemic inflammation in children: the ACFIES study. BMC Pediatrics 2016 16:31 